\title{
Ethanol Reversal of Tolerance to the Antinociceptive Effects of Oxycodone and Hydrocodone
}

\author{
Joanna C. Jacob, Justin L. Poklis, Hamid I. Akbarali, Graeme Henderson, \\ and William L. Dewey
}

Department of Pharmacology and Toxicology, Virginia Commonwealth University, Richmond, Virginia- (J.C.J., J.L.P., H.I.A., W.L.D.); and School of Physiology, Pharmacology and Neuroscience, University of Bristol, Bristol, United Kingdom (G.H.)

Received February 28, 2017; accepted April 20, 2017

\begin{abstract}
This study compared the development of tolerance to two orally bioavailable prescription opioids, oxycodone and hydrocodone, to that of morphine, and the reversal of this tolerance by ethanol. Oxycodone (s.c.) was significantly more potent in the mouse tailwithdrawal assay than either morphine or hydrocodone. Oxycodone was also significantly more potent in this assay than hydrocodone when administered orally. Tolerance was seen following chronic subcutaneous administration of each of the three drugs and by the chronic administration of oral oxycodone, but not following the chronic oral administration of hydrocodone. Ethanol (1 g/kg i.p.) significantly reversed the tolerance to the subcutaneous administration of each of the three opioids that developed when given 30 minutes prior to challenge doses. It took twice as much ethanol, when given orally, to reverse the
\end{abstract}

tolerance to oxycodone. We investigated whether the observed tolerance to oxycodone and its reversal by ethanol were due to biodispositional changes or reflected a true neuronal tolerance. As expected, a relationship between brain oxycodone concentrations and activity in the tail-immersion test existed following administration of acute oral oxycodone. Following chronic treatment, brain oxycodone concentrations were significantly lower than acute concentrations. Oral ethanol $(2 \mathrm{~g} / \mathrm{kg})$ reversed the tolerance to chronic oxycodone, but did not alter brain concentrations of either acute or chronic oxycodone. These studies show that there is a metabolic component of tolerance to oxycodone; however, the reversal of that tolerance by ethanol is not due to an alteration of the biodisposition of oxycodone, but rather is neuronal in nature.

\section{Introduction}

Prescription opioids, such as oxycodone, were responsible for over half of the reported 28,000 opioid overdose deaths in 2014. Individuals who abuse prescription opioids often use other substances, leading to polydrug abuse (Ogbu et al., 2015). Ethanol is one of the most common drugs coabused by opioid users, despite the long-standing warning that ethanol and opioids pose a significant health risk when taken together (Karch and Drummer, 2001; Oliver et al., 2007). Multiple postmortem analyses have shown that individuals who consumed opioids such as heroin along with alcohol died from blood opioid concentrations measuring significantly lower than those who died from an opioid without alcohol consumption (Darke and Hall, 2003). Additionally, a separate study that specifically investigated oxycodone-related overdoses reported that deaths resulting from the combined intake of oxycodone and ethanol were ruled to be exclusively accidental, rather than intentional (Thompson et al., 2008). Although it is possible that a general lack of awareness exists among opioid users regarding the dangers related to coconsumption of

This work was supported by the National Institutes of Health National Institute on Drug Abuse [Grants T32 DA007027, R01 DA036975, and P30 DA033934]

https://doi.org/10.1124/jpet.117.241083. ethanol with opioids, it is likely that these individuals experience some enhancement of opioid effects when used together, leading to riskier drug-taking behavior to offset the tolerance(s) developed to the opioids. Postmortem studies reported findings from blood levels extracted from peripheral sites, such as the femoral artery and heart blood. Collection of postmortem blood is easy to obtain, and samples are reliably quantified; however, it is important to recognize that the lethal event during opioid overdose is respiratory depression - a centrally mediated effect controlled primarily in the brainstem where opioid receptor density is quite high (Delfs et al., 1994; Satoh and Minami, 1995). One hypothesis relating to the increased lethality of oxycodone when ethanol was also detected in presumed opioid-tolerant individuals is that ethanol alters the kinetics of oxycodone. Therefore, it was important to investigate if in fact the distribution and concentration of oxycodone in the brain are altered by ethanol administration.

Ethanol is also known to reverse various tolerances to morphine, including the antinociceptive and respiratory depressive effects, which may be explained by mechanisms that involve protein kinase $\mathrm{C}$ and $\mathrm{GABA}_{\mathrm{A}}$ and $\mathrm{GABA}_{\mathrm{B}}$ receptor signaling (Hull et al., 2013; Hill et al., 2016). Additionally, recent evidence has shown that ethanol was unable to reverse the respiratory depressive tolerance to methadone, suggesting 
that certain opioids may be more susceptible to ethanol's reversal effects than others (Withey et al., 2017). Our goal for the studies presented here was to compare the effects of ethanol reversal as seen previously in morphine-tolerant mice to those in mice made tolerant to two other commonly abused opioids, oxycodone and hydrocodone, to determine if they are more "morphine-like" or more "methadone-like" in regards to their interaction with ethanol.

These drugs, similar to morphine and heroin, have been shown to exert their analgesic and respiratory depressive effects through similar pathways and mechanisms involving the $\mu$-opioid receptor. However, there are a number of unique properties belonging to oxycodone and hydrocodone that set them apart from morphine beyond slight structural differences, such as varying degrees of oral bioavailability and their primary enzymatic degradation pathways (Reisine and Pasternak, 1996; Kolesnikov et al., 2003). Discrepancies exist in the literature regarding which opioid receptor mediates oxycodone's antinociceptive effects, with studies carried out in rats supporting a primary role of the kappa receptor based on in vitro binding studies and behavioral assessments (Nielsen et al., 2007). Studies utilizing in vitro and in vivo approaches in mice, however, showed the $\mu$-opioid receptor is the primary receptor type that is preferentially bound and activated by oxycodone (Yoburn et al., 1995). Additionally, it was shown that, in the tail-flick assay, neither norbinaltorphimine nor naltrindole (the $\kappa$-opioid receptor and $\delta$-opioid receptor antagonists, respectively) was unable to block the antinociceptive properties of oxycodone (Beardsley et al., 2004). Given the differences underlying the pharmacodynamics and pharmacokinetics of these opioid compounds, it was of interest to determine if ethanol reversed analgesic tolerance to both of these compounds, and to what degree each of the compounds were susceptible to ethanol's reversal effects.

\section{Materials and Methods}

Drugs and Chemicals. Morphine sulfate, oxycodone $\mathrm{HCl}$, and hydrocodone bitartrate were obtained from the National Institutes of Health National Institute on Drug Abuse (Bethesda, MD). Morphine sulfate, oxycodone $\mathrm{HCl}$, and hydrocodone bitartrate were each dissolved in pyrogen-free isotonic saline (Hospira, Lake Forest, IL). Ethanol was obtained from AAPER Ethanol and Chemical Co. (Shelbyville, KY) and was diluted with pyrogen-free isotonic saline.

Animals. Male Swiss Webster mice (Harlan Laboratories, Indianapolis, IN) weighing 25-30 g were housed five to a cage in animal-care quarters and maintained at $22 \pm 2^{\circ} \mathrm{C}$ on a 12-hour light-dark cycle. Food and water were available ad libitum. The mice were brought to the test room $\left(22 \pm 2^{\circ} \mathrm{C}, 12\right.$-hour light-dark cycle), marked for identification, and allowed 18 hours to recover from transport and handling. Protocols and procedures were approved by the Institutional Animal Care and Use Committee at Virginia Commonwealth University Medical Center and comply with the recommendations of the International Association for the Study of Pain.

Tail-Immersion Test. The warm-water tail-immersion test was performed using a water bath with the temperature stabilized at $56 \pm$ $0.1^{\circ} \mathrm{C}$ (Coderre and Rollman, 1983). The experimenter determined the control latencies, then injected the mice and assessed test latencies 20 minutes following opioid treatment. Only mice with a control latency between 2.00 and 4.00 seconds were used. A 10.00-second maximum cutoff time was used to prevent tissue damage. Antinociception was quantified as the percentage of maximum possible effect (\%MPE), which was calculated as follows: $\% \mathrm{MPE}=[$ (test latency - control latency) $/$ $(10-$ control latency) $] \times 100$. \% MPE was calculated for each mouse using at least six mice per dose of drug (Harris and Pierson, 1964).
Acute Dose-Response Curves in Tail-Immersion Test: Oxycodone, Hydrocodone, and Morphine. Male Swiss Webster mice were weighed and baseline tail-withdrawal latencies were recorded as described earlier. Oxycodone was administered subcutaneously at doses of $0.25,0.5,1.0,1.25$, and $1.5 \mathrm{mg} / \mathrm{kg}$, and mice were returned to their home cages. Hydrocodone was administered subcutaneously at doses of $1.0,3.0,5.0$, and $6.0 \mathrm{mg} / \mathrm{kg}$, and mice were returned to their home cages. Morphine was administered subcutaneously at doses of $2.0,4.0,8.0$, and $16 \mathrm{mg} / \mathrm{kg}$, and mice were returned to their home cages. After a 20-minute pretreatment period, mice were retested for tail-withdrawal latencies to assess antinociceptive effects and to construct dose-response curves.

Single-Day Tolerance Model. Antinociceptive tolerance to oxycodone and hydrocodone was developed based on a paradigm we have used in previous studies, where the respective acute $\mathrm{ED}_{80}$ for each compound was chosen as the maintenance dose used for chronic studies (Hull et al., 2010). Mice were injected s.c. once every hour (for a total of seven injections) with the respective acute $\mathrm{ED}_{80}$ dose of each opioid corresponding to the tail-immersion test, $1.25 \mathrm{mg} / \mathrm{kg}$ for oxycodone and $5.0 \mathrm{mg} / \mathrm{kg}$ for hydrocodone, and saline in control mice. One hour after the final injection, mice were administered ethanol $(1 \mathrm{~g} / \mathrm{kg})$ or $0.9 \%$ saline vehicle by i.p. injection and 30 minutes later were challenged with various subcutaneous doses of oxycodone (ascending $\log _{2}$ doses from 0.25 to $4.0 \mathrm{mg} / \mathrm{kg}$ ) or hydrocodone (ascending $\log _{2}$ doses from 1 to $16 \mathrm{mg} / \mathrm{kg}$ ) to construct dose-response curves for calculation of $\mathrm{ED}_{50}$ values and potency ratios. The dose of ethanol and pretreatment time were chosen based on previous methods used in our laboratory (Hull et al., 2013).

Four-Day Tolerance Model. Tolerance to oral oxycodone or hydrocodone was developed using a twice-daily gavage method whereby animals were administered oxycodone $[64 \mathrm{mg} / \mathrm{kg}$ by mouth (PO)] or hydrocodone ( $128 \mathrm{mg} / \mathrm{kg} \mathrm{PO}$ ) in the morning and again in the evening, with at least 8 hours separating the two gavage events. This protocol was adapted from a previously published protocol used to develop tolerance to morphine (Bernstein and Welch, 1998). Animals were weighed on days 1,3 , and 5 (test day), and dosing was adjusted accordingly. The evening gavage administration on day 4 was the final maintenance dose animals received prior to test and challenge treatments on day 5. Drug dose was calculated for $0.1 \mathrm{ml} / 10 \mathrm{~g}$ body weight administration with $0.9 \%$ physiologic saline as the vehicle. All mice had continued access to ad libitum food and water throughout the dosing paradigm and remained group-housed in their home cages.

Oral Oxycodone Time Course. A time-course study was conducted to assess the antinociceptive effects of oral oxycodone following a single gavage of $16 \mathrm{mg} / \mathrm{kg}$ oxycodone at the following time points: $5,10,20,30,60,120,240$, and 480 minutes. Here, five mice were repeatedly tested to determine average $\% \mathrm{MPE}$ at each time point. Utilizing the same time points and dose of oxycodone, we repeated the time-course study to assess brain oxycodone concentrations. An $N$ of 5 mice per time point was used for the brain concentration analysis.

Reagents for Gas Chromatography Mass Spectrometry Analysis. The primary reference materials oxycodone and oxycodone$\mathrm{d}_{6}$ were purchased from Cerilliant Corporation (Round Rock, TX) as metabolic solutions. Chloroform, deionized water, hydroxamine hydrochloride ( $\mathrm{HCl}$ ), 2-propanol, sodium bicarbonate, and sodium carbonate were purchased form Fisher Scientific (Hanover Park, IL). $\mathrm{N}, \mathrm{O}$-bis(trimethylsilyl)-trifluoroacetamide $+10 \%$ trimethylchlorosilane was purchased from Regis Technologies (Morton Grove, IL).

Sample Extraction. Quantitative analysis of oxycodone was based upon a previously described method (Broussard et al., 1997; Wolf and Poklis, 2010). This method is routinely performed in our laboratory for the analysis of opiates in blood and tissue samples. Preextraction preparation was unnecessary for the whole-blood specimens. Whole brain tissue specimens were diluted as 1 part tissue to 3 parts deionized water ( $\mathrm{v} / \mathrm{v})$ and homogenized. Matched matrix fivepoint calibration curves containing opiates of interest were prepared at $20-1000 \mathrm{ng} / \mathrm{ml}$ for blood or $20-1000 \mathrm{ng} / \mathrm{g}$ for tissue, along with blank and double-blank controls. Ten microliters of internal standard 
consisting of $10 \mu \mathrm{g} / \mathrm{ml}$ (100 $\mathrm{ng}$ total) of oxycodone- $\mathrm{d}_{6}$ was added to $1.0-\mathrm{ml}$ or $1.0 \mathrm{-g}$ aliquots of calibrators, controls, and specimens, except the double-blank control. Ten percent hydroxamine $\mathrm{HCl}(0.2 \mathrm{ml})$ was added to each of the samples, which were then mixed and heated at $30^{\circ} \mathrm{C}$ for 30 minutes. Samples were then cooled, and $1.0 \mathrm{ml}$ of saturated carbonate/bicarbonate buffer (1:1, N:N, pH 9.5) and $2.0 \mathrm{ml}$ of chloroform:2-propanol (8:2) were added. Samples were mixed for 5 minutes and then centrifuged at $2500 \mathrm{rpm}$ for 5 minutes. The top aqueous layer was aspirated and the organic layer was transferred to a clean test tube and evaporated to dryness at $40^{\circ} \mathrm{C}$ under a constant stream of nitrogen. $\mathrm{N}, \mathrm{O}$-bis(trimethylsilyl)-trifluoroacetamide $+10 \%$ trimethylchlorosilane $(50 \mu \mathrm{l})$ was added, and the samples were heated for 30 minutes at $70^{\circ} \mathrm{C}$. The samples were then placed in autosampler vials for gas chromatography mass spectrometry analysis.

Instrumental Analysis. The gas chromatography mass spectrometry analysis was performed with a Hewlett Packard 6890 with a split/splitless injection port attached to Hewlett Packard model 5793A mass selective detector with a 7683 autosampler (Hewlett Packard, Palo Alto, CA). The chromatographic separation was performed on an Agilent (Santa Clara, CA) HP-1 $12 \mathrm{~m} \times 0.2 \mathrm{~mm} \times 0.33 \mu \mathrm{m}$ analytical column with the injection temperature set to $170^{\circ} \mathrm{C}$ and run in pulsed splitless mode. The initial oven temperature was $170^{\circ} \mathrm{C}$ and was held for 1.0 minute, then heated at $10^{\circ} \mathrm{C} / \mathrm{min}$ to $280^{\circ} \mathrm{C}$. The total run time was 12 minutes. The quantification and qualifying ions monitored for oxycodone were 269,459 , and $474 \mathrm{~m} / z$, and 465 and $480 \mathrm{~m} / z$ for oxycodone- $\mathrm{d}_{6}$. A linear regression of the ratio of the peak area counts of quantification ion of internal standard versus concentration was used to construct the calibration curves.

Data Analysis. Opioid dose-response curves were constructed for calculation of $\mathrm{ED}_{50}$ values by the Bliss (1967) method, utilizing leastsquares linear regression analysis followed by calculation of $95 \%$ confidence limits. For all other statistical analyses, GraphPad Prism 5 was used (GraphPad Software, La Jolla, CA). All data are presented as the mean \pm standard error of the mean. A one-way analysis of variance (ANOVA) with Tukey's post-hoc analysis was used when comparing changes across three or more groups over a single factor. Statistical differences between only two groups of data were analyzed using Student's two-tailed unpaired $t$ test. Differences were considered significant when $P<0.05$.

\section{Results}

\section{Acute Effects of Oxycodone and Hydrocodone}

To test acute antinociceptive properties, oxycodone or hydrocodone was administered subcutaneously and assessed in the warm-water tail-withdrawal test. Tail-withdrawal latencies dose dependently increased, reaching a ceiling effect at $1.5 \mathrm{mg} / \mathrm{kg}$ for oxycodone and at $6.0 \mathrm{mg} / \mathrm{kg}$ for hydrocodone, where all animals exhibited an MPE of $100 \%$. The $\mathrm{ED}_{50}$ value for acute oxycodone was calculated to be $0.84 \mathrm{mg} / \mathrm{kg}(0.68-1.04)$. The $\mathrm{ED}_{50}$ value for hydrocodone was calculated to be $3.95 \mathrm{mg} / \mathrm{kg}$ (2.40-6.52). Morphine was administered subcutaneously, and all mice reached $100 \% \mathrm{MPE}$ at $8 \mathrm{mg} / \mathrm{kg}$. The $\mathrm{ED}_{50}$ was calculated to be $3.94 \mathrm{mg} / \mathrm{kg}$ (3.55-4.36). As predicted, we found that oxycodone was significantly more potent than hydrocodone and morphine, and hydrocodone was equally as potent as morphine when administered subcutaneously in mice.

We then compared the potencies of oxycodone and hydrocodone when given orally due to their reliable oral bioavailability. Acutely, oxycodone produced an oral $\mathrm{ED}_{50}$ of $9.29 \mathrm{mg} / \mathrm{kg}$ (7.18-12.02), 10 times greater than its subcutaneous $\mathrm{ED}_{50}$ value and thus significantly less potent. In subsequent experiments comparing chronic saline-treated (i.e., control) versus chronic oxycodone-treated mice, a similar $\mathrm{ED}_{50}$ value of $8.29 \mathrm{mg} / \mathrm{kg}(6.12-11.52)$ was obtained in the control mice, indicating acute oral oxycodone $\mathrm{ED}_{50}$ values are reliably reproducible (Table 1 ). Orally administered hydrocodone produced an $\mathrm{ED}_{50}$ value also nearing 10 times the subcutaneous value, equaling $38.79 \mathrm{mg} / \mathrm{kg}$ (29.21-51.53) (Table 1). Hydrocodone given orally was significantly less potent than when given subcutaneously.

\section{Tolerance Developed to Oxycodone and Hydrocodone Following Repeated Administration}

Oxycodone Tolerance. Chronic injections of s.c. saline prior to s.c. oxycodone challenge doses yielded a dose-response curve of oxycodone with an $\mathrm{ED}_{50}$ value of $0.90 \mathrm{mg} / \mathrm{kg}$ (0.72-1.12), reproducing what was observed in our acute dose-response experiments, suggesting no adverse effects of handling or repeated vehicle injections on oxycodone's antinociceptive effect. In mice repeatedly administered s.c. oxycodone prior to receiving s.c. oxycodone challenge doses, the $\mathrm{ED}_{50}$ value was $1.70 \mathrm{mg} / \mathrm{kg}$ (1.42-2.03), which was significantly shifted to the right compared with the mice that received chronic saline, indicating tolerance was observed (Fig. 1A). We further characterized oxycodone tolerance development by investigating the response to repeated oral oxycodone. A modified protocol with repeated exposure across 4 days, rather than repeated exposure within a single day, was used for this experiment. We found a significant shift to the right in response to chronic oral oxycodone with an $\mathrm{ED}_{50}$ value of $33.41 \mathrm{mg} / \mathrm{kg}(25.50-44.17)$ compared with the acute $\mathrm{ED}_{50}$ value of $8.29 \mathrm{mg} / \mathrm{kg}(6.12-11.52)$ reported earlier, demonstrating that these mice were tolerant to the antinociceptive effects of orally administered oxycodone (Table 1).

Hydrocodone Tolerance. Chronic s.c. injections of saline followed by acute challenge doses of s.c. hydrocodone generated a dose-response curve with an $\mathrm{ED}_{50}$ value of $3.92 \mathrm{mg} / \mathrm{kg}$ (3.26-4.71) (Fig. 1B) in mice, similar to what was observed in previous acute dose-response experiments as stated earlier.

TABLE 1

Comparison of tolerance development and ethanol reversal of various opioid compounds

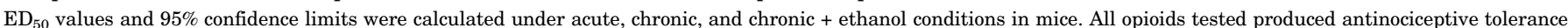

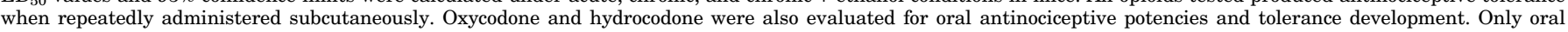
oxycodone produced significant tolerance to itself after repeated administration.

\begin{tabular}{|c|c|c|c|c|c|}
\hline & Morphine s.c. & Oxycodone s.c. & Oxycodone PO & Hydrocodone s.c. & Hydrocodone PO \\
\hline & $m g / k g$ & $m g / k g$ & $m g / k g$ & $m g / k g$ & $m g / k g$ \\
\hline Acute $\mathrm{ED}_{50}$ & $4.80(2.5-5.7)$ & $0.89(0.72-1.12)$ & $8.29(6.12-11.52)$ & $3.92(3.26-4.71)$ & $38.79(29.21-51.53)$ \\
\hline Chronic $\mathrm{ED}_{50}$ & $19.90 *(14.8-29.1)$ & $1.70 *(1.42-2.03)$ & $33.41 *(25.50-44.17)$ & $9.01 *(6.44-12.62)$ & $55.92(40.63-76.96)$ \\
\hline Chronic + ethanol $\mathrm{ED}_{50}$ & $5.20(4.9-5.5)$ & $1.02(0.77-1.37)$ & $35.52(20.19-59.03)$ & $4.73(3.51-6.38)$ & N/A \\
\hline
\end{tabular}

N/A, not assessed.

*Significant shift from acute $\mathrm{ED}_{50}$ values, determined by confidence limits that no longer overlap. 

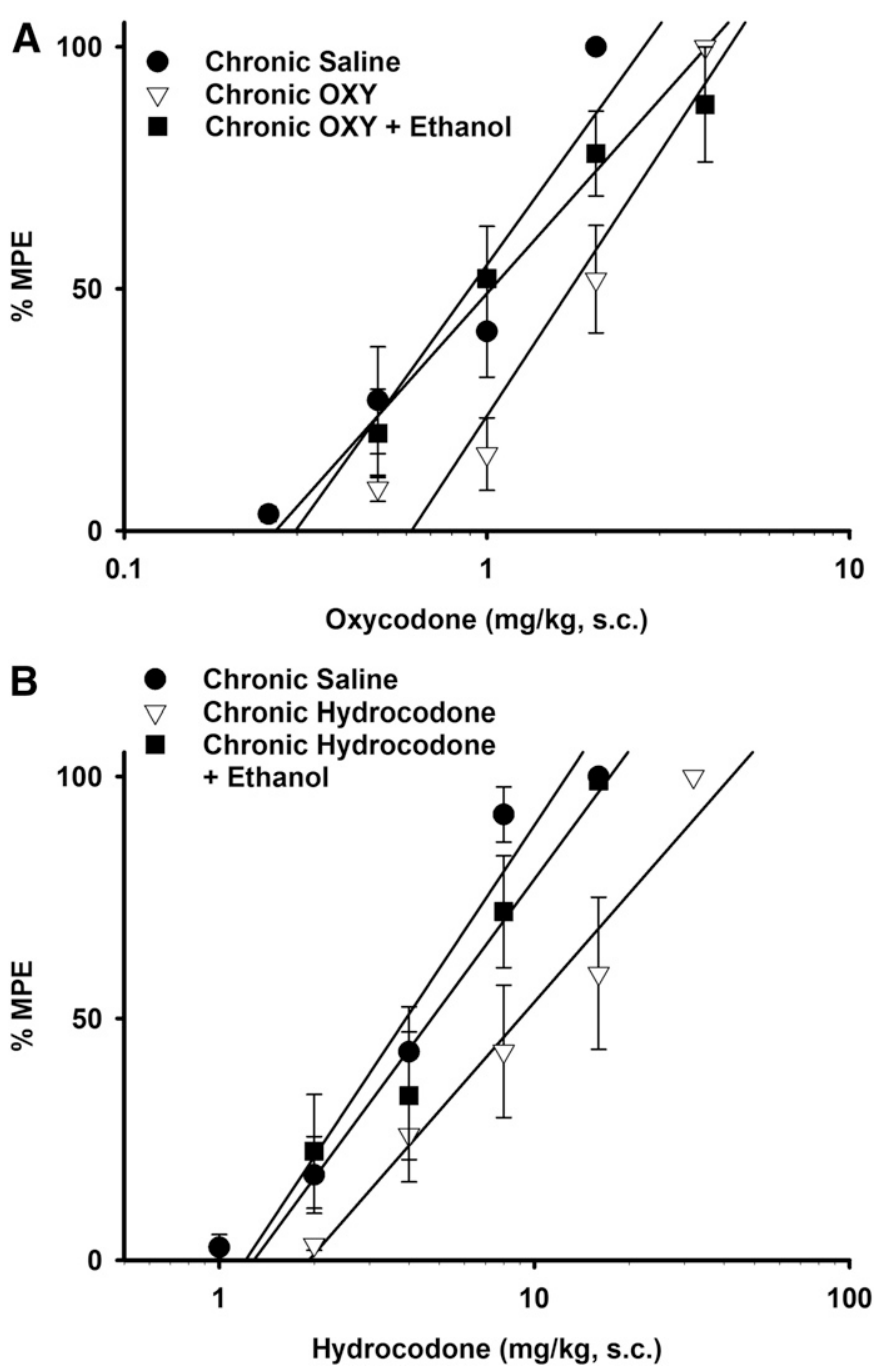

Fig. 1. Ethanol reversal of oxycodone and hydrocodone tolerance. Ethanol (1 g/kg, i.p.) fully reversed both oxycodone (A) and hydrocodone (B) tolerance. Each data point is represented by a minimum of five mice and presented as the mean \pm S.E.M. Animals were injected once hourly with either saline or an $\mathrm{ED}_{80}$ dose of oxycodone or hydrocodone s.c. for 6 hours, followed by an i.p. injection of ethanol $(1 \mathrm{~g} / \mathrm{kg})$ or saline 1 hour later. Thirty minutes later, various challenge doses of oxycodone or hydrocodone were injected s.c. to construct dose-response curves and generate $\mathrm{ED}_{50}$ values.

The $\mathrm{ED}_{50}$ value significantly shifted to the right in animals chronically injected with hydrocodone prior to receiving the challenge injections, equaling $9.01 \mathrm{mg} / \mathrm{kg}$ (6.44-12.62), indicating tolerance developed in these mice. We also investigated the development of tolerance to oral hydrocodone and used a 4-day protocol similar to what was used for our chronic oral oxycodone studies. We observed an increase in the oral $\mathrm{ED}_{50}$ value, equaling $55.92 \mathrm{mg} / \mathrm{kg}$ (40.63-76.96); however, the confidence limits overlap those of the acute oral $\mathrm{ED}_{50}$ value [38.79 $\mathrm{mg} / \mathrm{kg}$ (29.21-51.53)], suggesting that complete tolerance was not observed in the oral dosing study (Table 1).

\section{Reversal of Oxycodone and Hydrocodone Antinociceptive Tolerance by Ethanol (i.p.)}

We tested ethanol $(1 \mathrm{~g} / \mathrm{kg}$, i.p.) in mice repeatedly administered oxycodone or hydrocodone. Previously, our laboratory determined that a dose of $1 \mathrm{~g} / \mathrm{kg}$ ethanol was inert in the warm-water tail-withdrawal test but fully reversed morphine tolerance in mice (Hull et al., 2013). $\mathrm{ED}_{50}$ values were calculated from the resulting dose-response curves and compared across three conditions: chronic saline followed by saline and acute opioid challenge, chronic opioid followed by saline and opioid challenge, and chronic opioid followed by ethanol and opioid challenge. A single injection of ethanol ( $1 \mathrm{~g} / \mathrm{kg}$, i.p. $)$ significantly reversed antinociceptive tolerance to both oxycodone and hydrocodone (Fig. 1, A and B) as shown by the restoration of the $\mathrm{ED}_{50}$ values which closely resembled values observed in the acute dose-response experiments (Table 1). These results add to our previous findings that ethanol reversed the antinociceptive tolerance to morphine, suggesting that ethanol may interfere with a pathway common to some, but not all, opioids.

\section{Reversal of Oxycodone Antinociceptive Tolerance by Oral Ethanol}

Mice were assessed for oxycodone tolerance and reversal by PO ethanol in addition to i.p. ethanol, again utilizing the single-day tolerance paradigm. Mice that were repeatedly injected with s.c. oxycodone and received a saline gavage displayed tolerance to the antinociceptive effects in response to an oxycodone $(1.25 \mathrm{mg} / \mathrm{kg}$ s.c. $)$ challenge injection, as shown by a significantly lower \%MPE $(10.25 \pm 2.71 \% ; P<0.05$, oneway ANOVA) when compared with acute oxycodone controls $(50.98 \pm 11.95 \%)$. Mice that were repeatedly injected with s.c. oxycodone but received ethanol $(2 \mathrm{~g} / \mathrm{kg} \mathrm{PO})$ prior to receiving the challenge s.c. oxycodone injection continued to respond to oxycodone, displaying antinociceptive responses similar to those of both acute oxycodone-treated mice and oxycodonetreated mice that received i.p. ethanol $(1 \mathrm{~g} / \mathrm{kg})$. The \%MPE values observed in both of these chronic oxycodone plus ethanol treatment groups were significantly higher compared with those of the chronic oxycodone plus saline treatment group $(2 \mathrm{~g} / \mathrm{kg}$ ethanol PO, $63.90 \pm 16.88 \%, P<0.05$ and $1 \mathrm{~g} / \mathrm{kg}$ ethanol, i.p., $71.49 \pm 11.83 \%, P<0.01$; one-way ANOVA) (Fig. 2 ). These data indicate that both i.p. and $P O$ ethanol significantly reversed oxycodone tolerance.

\section{Pharmacokinetic Studies}

Acute Oral Oxycodone Time Course: Antinociception and Brain Concentrations. Oxycodone $(16 \mathrm{mg} / \mathrm{kg}$, PO) was detectable in the brain at the earliest time point measured (5 minutes), averaging $80.2 \mathrm{ng} / \mathrm{g}$, whereas antinociception was marginal at $10.14 \% \mathrm{MPE}$ on average. Peak brain concentrations were observed at 20 and 30 minutes following oxycodone administration, measuring 153.58 and $153.24 \mathrm{ng} / \mathrm{g}$, respectively. Brain concentrations at these times were significantly higher than concentrations detected at 120 minutes $(P<0.05)$ and 480 minutes $(P<0.001$; one-way ANOVA). Significant antinociception was detected at the 20-, 30-, and 60-minute time points but not at the 5 -minute time point $[(P<0.05$ (20 minutes) and $P<0.001$ (30 and 60 minutes), one-way ANOVA]. Peak antinociception, measured as $100 \% \mathrm{MPE}$, was not detected until 30 minutes following administration, and persisted until the 60 -minute point. Antinociception at $20(P<$ $0.05), 30$, and 60 minutes following oxycodone was significantly higher than at 480 minutes $(P<0.0001)$, with the 30 and 60-minute time points also significantly higher than at 240 minutes $(P<0.001$, one-way ANOVA). However, brain 


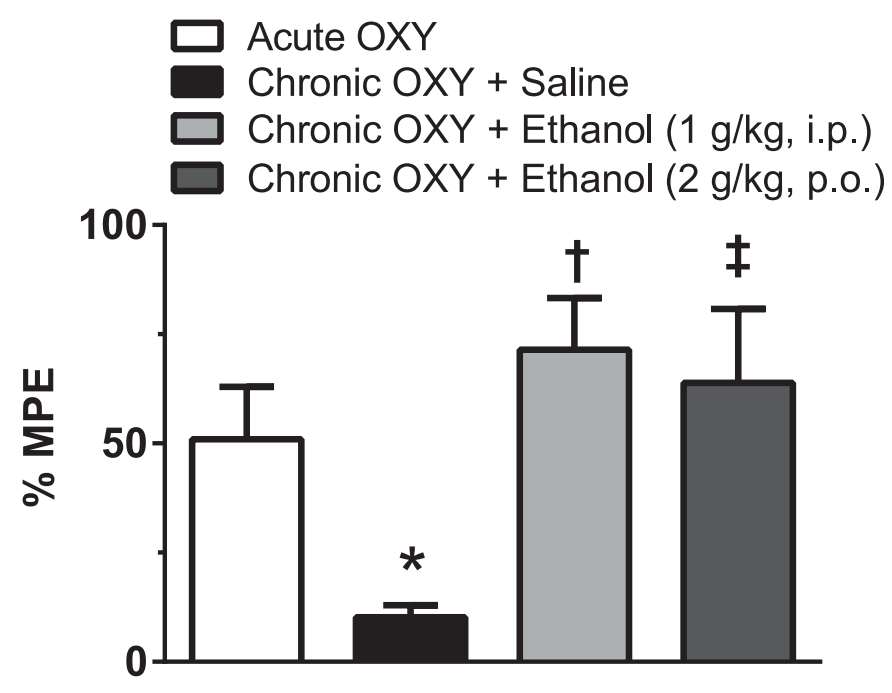

Oxycodone [1.25 mg/kg, s.c.]

Fig. 2. Intraperitoneal and oral ethanol reversed antinociceptive tolerance to subcutaneous oxycodone. Mice were chronically injected with oxycodone $(1.25 \mathrm{mg} / \mathrm{kg}$, s.c.) or saline hourly for 6 hours and treated with saline, i.p. ethanol $(1 \mathrm{~g} / \mathrm{kg})$, or PO ethanol $(2 \mathrm{~g} / \mathrm{kg})$ prior to receiving a challenge injection of oxycodone $(1.25 \mathrm{mg} / \mathrm{kg}$, s.c.). Antinociception was assessed using the tail-immersion assay, where significant tolerance was displayed in mice chronically treated with oxycodone and no ethanol, compared with the acute oxycodone treatment group $\left({ }^{*} P<0.05\right.$, one-way ANOVA). Two additional groups of mice were treated with repeated injections of oxycodone, but received either an injection of ethanol $(1 \mathrm{~g} / \mathrm{kg}$, i.p.) or a gavage of ethanol $(2 \mathrm{~g} / \mathrm{kg}, \mathrm{PO}) 30$ minutes prior to receiving an oxycodone challenge injection. Ethanol treatment in these mice reversed tolerance development to oxycodone as seen by a restored response to the antinociceptive effects of oxycodone. Chronic oxycodone-treated mice given either i.p. ethanol $(† P<0.01)$ or oral ethanol $(\ddagger P<0.05)$ displayed significantly greater antinociceptive effects in response to a challenge injection of oxycodone compared with chronic oxycodone mice given saline prior to an oxycodone challenge (one-way ANOVA). All groups are represented by a minimum of five mice with data shown as the mean \pm S.E.M.

oxycodone concentrations at 60 minutes were markedly lower, measuring closer to the 5- and 10-minute time points on average, although the antinociceptive effects were vastly greater. Notably, oxycodone was not detectable in any of the brain tissue samples tested 480 minutes ( 8 hours) after a single gavage, and there was no antinociception at this time (Fig. 3).

Brain Oxycodone Concentrations Did Not Correlate With Antinociception. We compared brain concentrations of oxycodone when given orally versus subcutaneously using equianalgesic doses. Both subcutaneously and orally administered oxycodone produced near 80\%MPE. Subcutaneous oxycodone $(1.25 \mathrm{mg} / \mathrm{kg})$ produced $74.48 \% \mathrm{MPE}$, whereas oral oxycodone (16 mg/kg) produced $77.71 \% \mathrm{MPE}$. Brain oxycodone concentrations averaged $348.89 \mathrm{ng} / \mathrm{g}$ following subcutaneous administration, significantly higher than oral oxycodone concentrations, which averaged $114.1 \mathrm{ng} / \mathrm{g}(P<0.0001$, Student's two-tailed unpaired $t$ test). Our findings indicate that the antinociceptive effects of oxycodone are not directly correlated with brain oxycodone concentrations (Fig. 4).

Acute Brain Concentrations of Oxycodone After Oral Administration. Oxycodone was administered orally in ascending $\log _{2}$ doses ranging from 8 to $64 \mathrm{mg} / \mathrm{kg}$ to assess the dose-response relationship for brain concentrations. Brain

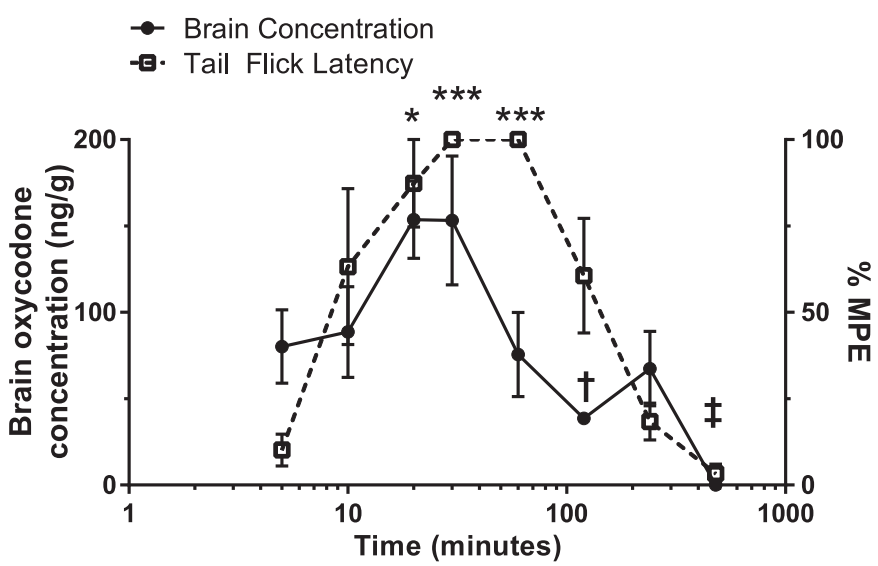

Fig. 3. Oral oxycodone time course: antinociception and brain concentration. After a single administration of oxycodone $(16 \mathrm{mg} / \mathrm{kg}, \mathrm{PO})$, brain oxycodone concentrations were plotted against oxycodone's antinociceptive effect in the warm-water tail-withdrawal assay at various time points ranging from 5 to 480 minutes. All data points represent the mean \pm S.E.M. from a minimum of five mice. Brain oxycodone concentrations increased during the first 20 minutes, where a plateau was observed until 30 minutes. Antinociception was slower to reach $100 \% \mathrm{MPE}$, which was not observed until 30 minutes and persisted until 60 minutes. Brain oxycodone concentrations at 60 minutes were much lower, measuring closer to the 5-minute time point, despite maximum antinociception. Significant observations for brain oxycodone concentrations were only noted at 120 - $(\dagger P<0.05)$ and 480 -minute $(\ddagger P<0.001)$ time points (oneway ANOVA), where concentrations were lower than all other time points. Antinociception was significantly higher at $20(* P<0.05), 30$, and 60 minutes $(* * * P<0.001)$ compared with 5 minutes. Antinociception at 30 and 60 minutes was significantly higher compared with $240(P<0.001)$ and 480 minutes $(P<0.0001)$.

concentrations showed an average of $114.1 \mathrm{ng} / \mathrm{g}(N=10)$, $312.4 \mathrm{ng} / \mathrm{g}(N=5)$, and $731.2 \mathrm{ng} / \mathrm{g}(N=14) 20$ minutes following administration of 16,32 , and $64 \mathrm{mg} / \mathrm{kg}$ oxycodone, respectively. Significant differences were detected between the 64 - and $16-\mathrm{mg} / \mathrm{kg}$ doses $(P<0.01$, one-way ANOVA). These findings demonstrated a general dose relationship with brain oxycodone concentrations following oral administration.

Brain Concentrations of Oral Oxycodone After Repeated Administration. The development of oral oxycodone tolerance was carried out over 4 days via twice-daily gavage administrations of oxycodone $(64 \mathrm{mg} / \mathrm{kg})$. Mice were challenged on day 5 with a single gavage of oxycodone $(16 \mathrm{mg} / \mathrm{kg})$. Brain concentrations 20 minutes following the challenge gavage showed an average of $28.92 \mathrm{ng} / \mathrm{g}(N=13)$. These concentrations were significantly lower than those seen after acute oxycodone $(16 \mathrm{mg} / \mathrm{kg})$ at the 20 -minute time point $(P<0.0001)$ (Fig. $5 \mathrm{~A})$.

The Effect of Oral Ethanol on Brain Concentrations of Acute Oral Oxycodone. To determine if ethanol alters acute oxycodone brain concentrations, mice were pretreated with ethanol $(2 \mathrm{~g} / \mathrm{kg}$, PO) 30 minutes prior to receiving a gavage of oxycodone (16 mg/kg). Mice were sacrificed $20 \mathrm{~min}$ utes following oxycodone administration, and brain samples were collected and processed immediately thereafter. After the oral administration of ethanol, brain concentrations averaged $304.7 \pm 90.8 \mathrm{ng} / \mathrm{g}$. Brain oxycodone concentrations were not significantly altered by acute ethanol, as compared with acute oxycodone alone $(P>0.05$, Student's two-tailed $t$ test) (Fig. 5B)

The Effect of Ethanol on Chronic Oxycodone Brain Concentrations. To determine if ethanol altered chronic oxycodone brain concentrations, mice were repeatedly 


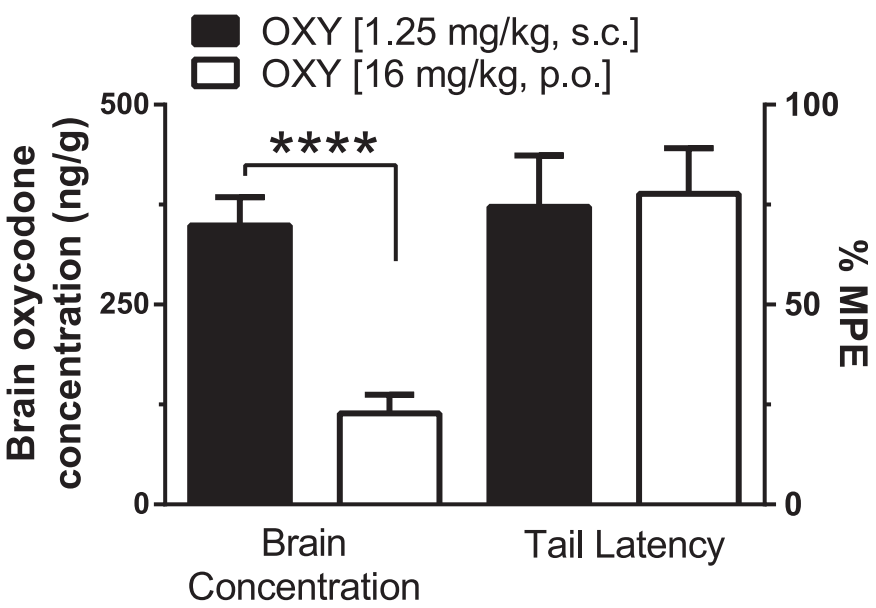

Fig. 4. Brain oxycodone concentrations do not correlate with antinociceptive effects of oxycodone. Mice were injected or gavaged with the respective $\mathrm{ED}_{80}$ dose of oxycodone $(1.25 \mathrm{mg} / \mathrm{kg}$, s.c. and $16 \mathrm{mg} / \mathrm{kg}$, PO). Both doses produced equal antinociception in mice; however, brain oxycodone concentrations significantly differed, with much higher concentrations detected after subcutaneous administration $(* * * * P<0.0001$, Student's unpaired two-tailed $t$ test). A minimum of five mice were used for each dose tested, with bars representing means \pm S.E.M.

administered oxycodone $(64 \mathrm{mg} / \mathrm{kg})$ twice daily for 4 days and pretreated on day 5 with a gavage of ethanol $(2 \mathrm{~g} / \mathrm{kg}, \mathrm{PO})$ 30 minutes prior to receiving a challenge gavage of oxycodone (16 mg/kg PO). Mice were sacrificed 20 minutes following oxycodone administration, and brain samples were collected and processed immediately thereafter. Brain oxycodone concentrations following chronic oxycodone administration plus acute administration of ethanol equaled $26.13 \pm 3.45 \mathrm{ng} / \mathrm{g}$ $(N=8)$ (Fig. 5C). Chronic oxycodone concentrations measured in the presence of ethanol were consistent with the chronic oxycodone samples measured in the absence of ethanol, providing supporting evidence that acute ethanol did not alter chronic oxycodone brain concentrations $(P>0.05$, unpaired Student's two-tailed $t$ test).

\section{Discussion}

Oxycodone and hydrocodone are two of the most commonly prescribed opioids for the relief of pain despite their untoward side effects, including tolerance development and abuse liability. Presently, an opioid abuse epidemic exists, in part, due to numerous individuals becoming dependent on prescription opioids, who then switch to heroin. When alcohol is consumed simultaneously with heroin, the risk of overdose and death increases. This could be due to one drug potentiating or adding to the depressant effects of the other, or due to the reversal of the tolerances to the opioid that have developed. We have previously shown that ethanol reversed morphine tolerance. The goal of this study was to compare the acute potency and propensity to produce tolerance, and assess reversal of that tolerance to oxycodone and hydrocodone by ethanol. A second goal was to elucidate if the tolerance was reversed due to an alteration of pharmacokinetic parameters.

We carried out a comprehensive study of the development of tolerance to prescription opioids and its reversal by ethanol in only male mice to minimize the variables being investigated. We realize that the abuse and overdose deaths caused by oxycodone and other opioids are a concern in both males and
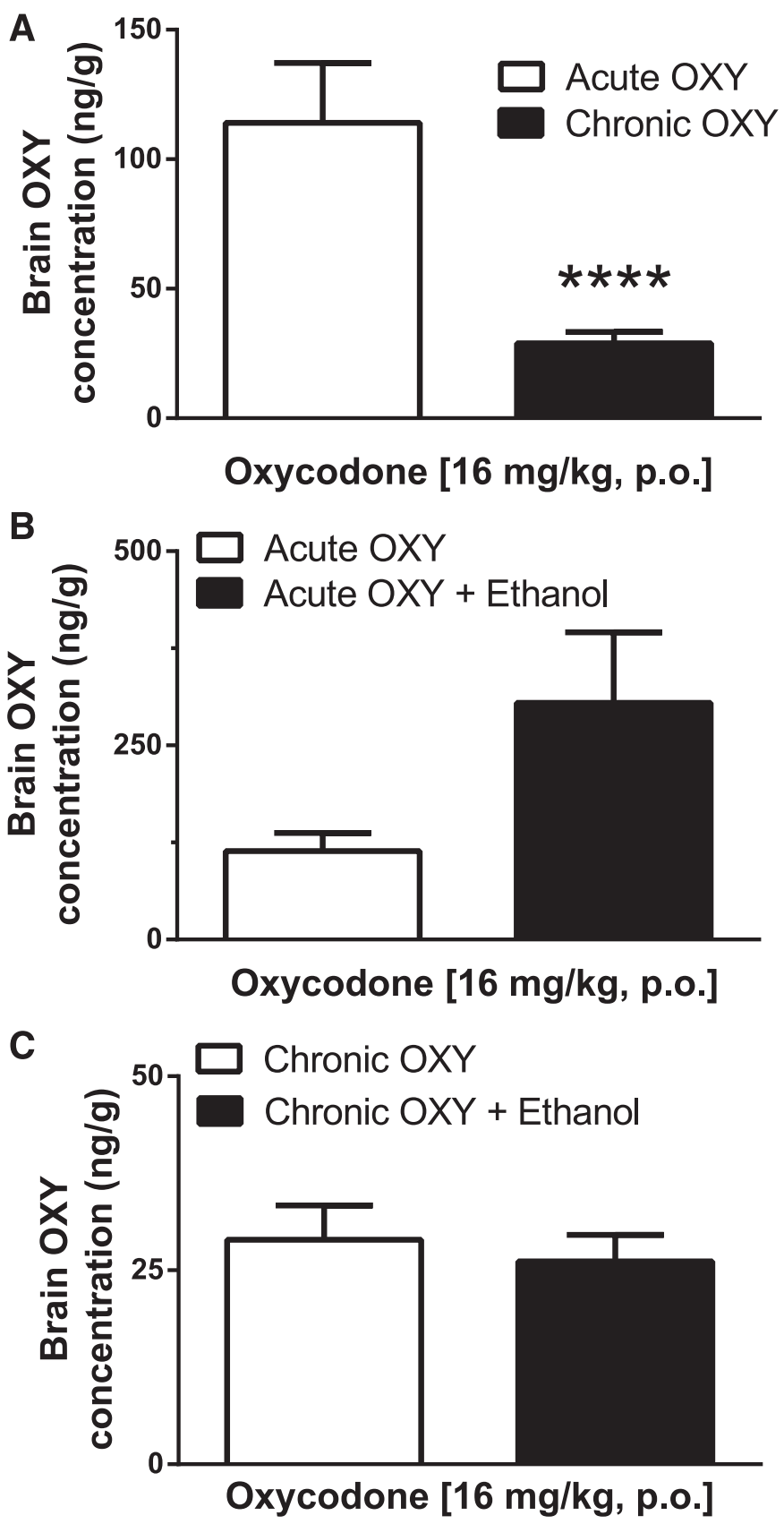

Fig. 5. Acute and chronic oxycodone brain concentrations. (A) Oxycodone brain concentrations 20 minutes following a challenge gavage of oxycodone $(16 \mathrm{mg} / \mathrm{kg})$ in mice either naïve to oxycodone or chronically treated with oxycodone $(64 \mathrm{mg} / \mathrm{kg}, \mathrm{PO})$ twice a day for 4 days. Acute concentrations represent the mean \pm S.E.M. of 10 mice, whereas chronic concentrations represent the mean \pm S.E.M. of 13 mice. Brain oxycodone concentrations detected 20 minutes following the oxycodone challenge were significantly lower in mice chronically treated with oxycodone compared with that of acutely treated mice $(* * * * P<0.001$, Student's twotailed unpaired $t$ test). (B) The effects of ethanol ( $2 \mathrm{~g} / \mathrm{kg}, \mathrm{PO})$ were assessed against acute oxycodone brain concentrations. Each bar represents the mean \pm S.E.M. of at least 10 mice. Ethanol did not have a significant effect $(P>0.05$, Student's unpaired two-tailed $t$ test), and both groups displayed similar brain oxycodone concentrations. (C) The effects of ethanol (2 g/kg, PO) were assessed against chronic oxycodone brain concentrations. Ethanol did not have a significant effect $(P>0.05$, Student's unpaired two tailed $t$ test), and both groups displayed similar brain oxycodone concentrations in response to a challenge oxycodone gavage $(16 \mathrm{mg} / \mathrm{kg})$ following chronic oxycodone treatment. Each bar represents the mean \pm S.E.M. of at least eight mice. 
females, and it is a limitation of this investigation to have limited these studies to only one gender. An enjoining project designed to compare multiple acute and chronic effects of these compounds in a battery of procedures is needed to comprehensively compare their effects in both genders. Similarly, we realize that deaths due to overdose of these compounds is due to respiratory depression, and this too is so important that it deserved a comprehensive investigation into the mechanism of tolerance development and its reversal by ethanol. This series of experiments is nearly complete and will be published in a separate paper in the near future.

Characterization of the Development of Oxycodone and Hydrocodone Antinociceptive Tolerance and the Effect of Ethanol on that Tolerance. Using a single-day injection schedule, mice were made tolerant to either oxycodone or hydrocodone. We found a 2-fold rightward shift in $\mathrm{ED}_{50}$ values in mice repeatedly injected with oxycodone. The doses we used produced similar levels of antinociception as seen in other studies, although a different outbred mouse strain (ICR) was used (Beardsley et al., 2004; Minami et al., 2009). Similarly, we found a 2-fold rightward shift in $\mathrm{ED}_{50}$ values in mice repeatedly injected with hydrocodone. Interestingly, our acute $\mathrm{ED}_{50}$ values for hydrocodone are between values reported by two other studies that used the radiantheat tail-flick assay rather than warm-water tail immersion. Kolesnikov et al. (2003) found an $\mathrm{ED}_{50}$ value of $1.37 \mathrm{mg} / \mathrm{kg}$ in Swiss Webster mice bred by a different vendor, whereas Navani and Yoburn (2013) calculated an $\mathrm{ED}_{50}$ value of $11 \mathrm{mg} / \mathrm{kg}$ in CD-1 mice.

Ethanol ( $1 \mathrm{~g} / \mathrm{kg}$, i.p.) was similarly effective in reversing the antinociceptive tolerance to both oxycodone and hydrocodone. In previous studies, this dose was also effective at reversing antinociceptive tolerance and respiratory depressive tolerance to morphine (Hull et al., 2013; Hill et al., 2016). Furthermore, $20 \mathrm{mM}$ in vitro ethanol reversed ex vivo morphine tolerance in the locus coeruleus of rats, suggesting that low-to-moderate ethanol doses reverse tolerance without eliciting effects acutely (Llorente et al., 2013).

Pharmacokinetic Analysis of Acute Oxycodone Time Course. We investigated the relationship between brain oxycodone concentrations and antinociceptive effects in mice. Previously, we have shown that there is a correlation between brain morphine concentrations and tail-flick latencies (Patrick et al., 1975, 1978). Oxycodone was detected in brain tissue 5 minutes after the oral administration of $16 \mathrm{mg} / \mathrm{kg}$, but antinociception was minimal. The concentration continued to increase until 20 minutes postgavage, where it remained steady for at least 10 more minutes, indicating peak concentrations for this dose of oxycodone were present in the brain. Significant antinociception was observed 20 minutes following oxycodone administration, with maximal or near maximal effects lasting from 20 to 60 minutes. Given that oxycodone was administered orally, it is not surprising that peak concentrations were not detected sooner. Additionally, mice were not food-restricted in these studies, and gastric emptying time could have altered or delayed the time to which oxycodone was actually absorbed and distributed through the liver and to the brain. In addition, at 60 minutes, oxycodone concentrations were lower, although not significantly, as compared with peak concentrations at 20 and 30 minutes. Between 30 and 60 minutes, there was a $50 \%$ decrease in oxycodone concentrations. The antinociceptive effects between 30 and 60 minutes, however, did not change and continued to produce $100 \%$ MPE. This discrepancy between brain concentrations of oxycodone and the antinociceptive effect measured likely suggests the presence of an active metabolite; however, our study did not investigate which metabolite(s) contributed to our observation. Oxycodone was not detected in the brain 8 hours after mice were dosed, and no antinociceptive effects were observed.

Brain Concentrations of Oxycodone After Chronic Administration. In chronic oxycodone-treated mice, brain oxycodone concentrations following a challenge gavage of $16 \mathrm{mg} / \mathrm{kg}$ were significantly lower compared with those observed in brains of mice that only received a single administration of the same dose of oxycodone. The effect was consistent, as demonstrated by the minimal variability between sample values, suggesting a well-regulated mechanism underlies oxycodone tolerance and metabolism. It is possible that, although initial variances in individual response are likely to occur upon acute exposure, highly regulated signaling events and selectively activated enzymatic pathways lead to more structured biologic responses upon repeated exposure. These data also provide further insight into the potential mechanisms underlying oxycodone tolerance. There could be a significant upregulation of degradative enzymes leading to the development of metabolic tolerance, and this warrants further investigation into this possible explanation. Additionally, the reduction in brain oxycodone concentrations after repeated administration could be a result of increased P-glycoprotein (P-gp) activity, a chaperone protein that actively transports drug molecules across the blood-brain barrier. P-gp is well characterized in its effects on opioid agonists (Dagenais et al., 2004), yet there are opposing reports regarding P-gp's actions on oxycodone. One study showed P-gp's ATPase activity was dose dependently increased by acute oxycodone and was upregulated after chronic oxycodone in rats (Hassan et al., 2007); however, another study showed that the P-gp inhibitor PSC833 had no effect on oxycodone's ability to enter and remain in the brain in rats (Bostrom et al., 2005). The contributions of the latter study's findings are difficult to interpret given that PSC833 has been shown to be less specific than previously thought (Mayer et al., 1997; Cvetkovic et al., 1999).

Acute and Chronic Oxycodone Pharmacokinetics Unaffected by Ethanol Coadministration in Mice. One of our main objectives in this study was to better characterize the effect of doses of ethanol that are moderately intoxicating in humans on acute and chronic brain oxycodone concentrations in mice. In our acute ethanol and acute oxycodone study, we found that oral ethanol at a dose of $2 \mathrm{~g} / \mathrm{kg}$ did not significantly alter oxycodone brain concentrations. It was of utmost importance to evaluate the effects of ethanol on brain oxycodone concentrations in chronic oxycodone-treated mice to address the primary health concern of polydrug abuse leading to opioid overdose. We tested oral ethanol $(2 \mathrm{~g} / \mathrm{kg})$ on chronic oxycodone brain concentrations. Somewhat unexpectedly, we observed that this dose of ethanol did not significantly alter oxycodone brain concentrations. These results in brain tissue differ from blood results from multiple human postmortem analyses, where the codetection of ethanol corresponded with significantly lower opioid levels in the blood compared with studies in which only opioids were detected at the time of death (Kerr et al., 2007; Darke, 2011). These data 
do, however, agree with and add to the previous observations of Hill et al. (2016), where ethanol (0.3 g/kg, i.p.) did not alter morphine brain or plasma concentrations in mice while still reversing the tolerance to respiratory depression, suggesting that ethanol does not work through mechanisms that alter the kinetics of either of these opiates. Furthermore, our findings were the result of acute ethanol effects on oxycodone brain concentrations, whereas repeated ethanol treatments might alter those findings. The effects of repeated ethanol have been tested on morphine behavioral responses and $\left[{ }^{3} \mathrm{H}\right]$ dihydromorphine binding in mice, where a change in affinity for striatal opioid receptors was observed after ethanol feeding (Tabakoff et al., 1981). Clearly, ethanol effects on opioid blood and brain concentrations in mice are dependent on treatment regimen and the specific opioid compound tested.

These studies show that there is a metabolic component underlying oxycodone tolerance, yet our results suggest the reversal of that tolerance by ethanol is not due to an alteration of the biodisposition of oxycodone. We therefore conclude that ethanol reversal of oxycodone tolerance is mediated by specific neuronal mechanisms, and future experiments will be conducted to address this finding.

\section{Acknowledgments}

The authors thank David Stevens for excellent technical assistance.

\section{Authorship Contributions}

Participated in research design: Jacob, Henderson, Akbarali, Dewey.

Conducted experiments: Jacob, Poklis.

Contributed new reagents or analytic tools: Poklis.

Performed data analysis: Jacob, Dewey.

Wrote or contributed to the writing of the manuscript: Jacob, Poklis, Henderson, Akbarali, Dewey.

\section{References}

Beardsley PM, Aceto MD, Cook CD, Bowman ER, Newman JL, and Harris LS (2004) Discriminative stimulus, reinforcing, physical dependence, and antinociceptive effects of oxycodone in mice, rats, and rhesus monkeys. Exp Clin Psychopharmacol 12:163-172.

Bernstein MA and Welch SP (1998) $\mu$-Opioid receptor down-regulation and cAMPdependent protein kinase phosphorylation in a mouse model of chronic morphine tolerance. Brain Res Mol Brain Res 55:237-242.

Bliss C (1967) Statistics in biology. Statistical methods for research in the natural sciences, McGraw-Hill, New York.

Boström E, Simonsson US, and Hammarlund-Udenaes M (2005) Oxycodone pharmacokinetics and pharmacodynamics in the rat in the presence of the P-glycoprotein inhibitor PSC833. J Pharm Sci 94:1060-1066.

Broussard LA, Presley LC, Pittman T, Clouette R, and Wimbish GH (1997) Simultaneous identification and quantitation of codeine, morphine, hydrocodone, and hydromorphone in urine as trimethylsilyl and oxime derivatives by gas chromatographymass spectrometry. Clin Chem 43:1029-1032.

Coderre TJ and Rollman GB (1983) Naloxone hyperalgesia and stress-induced analgesia in rats. Life Sci 32:2139-2146.

Cvetkovic M, Leake B, Fromm MF, Wilkinson GR, and Kim RB (1999) OATP and P-glycoprotein transporters mediate the cellular uptake and excretion of fexofenadine. Drug Metab Dispos 27:866-871.

Dagenais C, Graff CL, and Pollack GM (2004) Variable modulation of opioid brain uptake by P-glycoprotein in mice. Biochem Pharmacol 67:269-276.

Darke S (2011) The life of the heroin user: Typical beginnings, trajectories and outcomes. Cambridge University Press, Cambridge, UK

Darke S and Hall W (2003) Heroin overdose: research and evidence-based intervention. J Urban Health 80:189-200.
Delfs JM, Kong H, Mestek A, Chen Y, Yu L, Reisine T, and Chesselet MF (1994) Expression of mu opioid receptor mRNA in rat brain: an in situ hybridization study at the single cell level. J Comp Neurol 345:46-68.

Harris LS and Pierson AK (1964) Some narcotic antagonists in the benzomorphan series. J Pharmacol Exp Ther 143:141-148.

Hassan HE, Myers AL, Lee IJ, Coop A, and Eddington ND (2007) Oxycodone induces overexpression of P-glycoprotein (ABCB1) and affects paclitaxel's tissue distribution in Sprague Dawley rats. J Pharm Sci 96:2494-2506.

Hill R, Lyndon A, Withey S, Roberts J, Kershaw Y, MacLachlan J, Lingford-Hughes A, Kelly E, Bailey C, Hickman M, et al. (2016) Ethanol reversal of tolerance to the respiratory depressant effects of morphine. Neuropsychopharmacology 41:762-773.

Hull LC, Gabra BH, Bailey CP, Henderson G, and Dewey WL (2013) Reversal of morphine analgesic tolerance by ethanol in the mouse. J Pharmacol Exp Ther 345: 512-519.

Hull LC, Llorente J, Gabra BH, Smith FL, Kelly E, Bailey C, Henderson G, and Dewey WL (2010) The effect of protein kinase $\mathrm{C}$ and $\mathrm{G}$ protein-coupled receptor kinase inhibition on tolerance induced by mu-opioid agonists of different efficacy. J Pharmacol Exp Ther 332:1127-1135

Karch SB and Drummer O (2001) Karch's pathology of drug abuse, 4th ed, CRC Press, Boca Raton, FL.

Kerr T, Fairbairn N, Tyndall M, Marsh D, Li K, Montaner J, and Wood E (2007) Predictors of non-fatal overdose among a cohort of polysubstance-using injection drug users. Drug Alcohol Depend 87:39-45.

Kolesnikov YA, Wilson RS, and Pasternak GW (2003) The synergistic analgesic interactions between hydrocodone and ibuprofen. Anesth Analg 97: 1721-1723.

Llorente J, Withey S, Rivero G, Cunningham M, Cooke A, Saxena K, McPherson J, Oldfield S, Dewey WL, Bailey CP, et al. (2013) Ethanol reversal of cellular tolerance to morphine in rat locus coeruleus neurons. Mol Pharmacol 84:252-260.

Mayer U, Wagenaar E, Dorobek B, Beijnen JH, Borst P, and Schinkel AH (1997) Full blockade of intestinal P-glycoprotein and extensive inhibition of blood-brain barrier P-glycoprotein by oral treatment of mice with PSC833. J Clin Invest 100: $2430-2436$

Minami K, Hasegawa M, Ito H, Nakamura A, Tomii T, Matsumoto M, Orita S, Matsushima S, Miyoshi T, Masuno K, et al. (2009) Morphine, oxycodone, and fentanyl exhibit different analgesic profiles in mouse pain models. J Pharmacol Sci 111:60-72.

Navani DM and Yoburn BC (2013) In vivo activity of norhydrocodone: an active metabolite of hydrocodone. J Pharmacol Exp Ther 347:497-505.

Nielsen CK, Ross FB, Lotfipour S, Saini KS, Edwards SR, and Smith MT (2007) Oxycodone and morphine have distinctly different pharmacological profiles: radioligand binding and behavioural studies in two rat models of neuropathic pain. Pain 132:289-300.

Oliver P, Forrest R, and Keen J (2007) Does the Combined Use of Heroin or Methadone and Other Substances Increase the Risk of Overdose? (Research briefing, no. 27). National Treatment Agency for Substance Misuse, London.

Ogbu UC, Lotfipour S, and Chakravarthy B (2015) Polysubstance abuse: alcohol, opioids and benzodiazepines require coordinated engagement by society, patients, and physicians. West J Emerg Med 16:76-79.

Patrick GA, Dewey WL, Huger FP, Daves ED, and Harris LS (1978) Disposition of morphine in chronically infused rats: relationship to antinociception and tolerance. $J$ Pharmacol Exp Ther 205:556-562.

Patrick GA, Dewey WL, Spaulding TC, and Harris LS (1975) Relationship of brain morphine levels to analgesic activity in acutely treated mice and rats and in pellet implanted mice. J Pharmacol Exp Ther 193:876-883.

Reisine T and Pasternak GW (1996) Opioid analgesics and antagonists, in Goodman and Gilman's: The Pharmacological Basis of Therapeutics (Hardman J and Limbird L eds) pp 521-556, McGraw-Hill, New York.

Satoh M and Minami M (1995) Molecular pharmacology of the opioid receptors. Pharmacol Ther 68:343-364.

Tabakoff B, Urwyler S, and Hoffman PL (1981) Ethanol alters kinetic characteristics and function of striatal morphine receptors. $J$ Neurochem 37:518-521.

Thompson JG, Vanderwerf S, Seningen J, Carr M, Kloss J, and Apple FS (2008) Free oxycodone concentrations in 67 postmortem cases from the Hennepin County medical examiner's office. J Anal Toxicol 32:673-679.

Withey SL, Hill R, Lyndon A, Dewey WL, Kelly E, and Henderson G (2017) Effect of tamoxifen and brain-penetrant protein kinase $\mathrm{C}$ and c-Jun $\mathrm{N}$-terminal kinase inhibitors on tolerance to opioid-induced respiratory depression in mice. J Pharmacol Exp Ther 361:51-59.

Wolf C., and Poklis A. (2010). GC/MS analysis for morphine and other opiates in urine. Varian Application Note \#59.

Yoburn BC, Shah S, Chan K, Duttaroy A, and Davis T (1995) Supersensitivity to opioid analgesics following chronic opioid antagonist treatment: relationship to receptor selectivity. Pharmacol Biochem Behav 51:535-539.

Address correspondence to: William L. Dewey, Department of Pharmacology and Toxicology, Virginia Commonwealth University, 1112 East Clay Street, Richmond, VA 23298-0613. E-mail: william.dewey@vcuhealth.org 